\title{
A Novel Modeling based Agent Cellular Automata for Advanced Residential Mobility Applications
}

\author{
Elarbi Elalaouy*, Khadija Rhoulami \& Moulay Driss Rahmani \\ LRIT associated unit to CNRST (URAC ${ }^{\circ} 29$ ), Faculty of Science, Mohammed V University in Rabat \\ 4 Av.Ibn Battouta B.P. 1014 RP, 10006 Rabat, Morocco
}

\begin{abstract}
Nowadays, residential mobility (RM) is usually interconnected with other urban phenomena to give more realistic and effective to the simulation models in order to support urban planners and decision makers. Recent RM research works to describe models from a functional view; however researchers do less focus in providing software modeling of their RM applications. Based on this note, the article presents an agent cellular automata based modeling for advanced RM applications. The proposed modeling contains six models based on UML 2.0 diagrams which models parts of the system from different views. The work could be of interest for specialists (researchers, designers and developers) when modeling advanced RM applications.
\end{abstract}

Keywords-Residential mobility, multi agent systems, cellular automata; urban modeling

\section{INTRODUCTION}

Residential mobility (RM) is a very complex phenomenon that had first been studied as an independent system. This tendency is the classical point of view. However, the present tendency is focusing on to interconnect residential mobility with other urban phenomena with which it could give more realistic and effectiveness to the based simulation computer models in order to supporting urban planning and decision making. For example, authors of [1]-[4] had developed simulation's models integrating residential mobility, housing choice, population growth and land use change in order to simulate residential mobility for different duration of years.

Such research works of residential mobility do describe models from a functional view. They describe equations, functions, algorithms that run and simulate models. However, what could be noticed is that scholars do less focus on providing software modeling of their residential mobility' applications. Departing from this notice, this article propose a novel agent cellular automata based modeling for advanced residential mobility applications. This work gets benefit from development and coding experiments and apprehension of existent simulation models [1], [2], [5], [6].

Residential mobility, housing choice, population growth and land use dynamics are urban processes to be modeled; modeling such urban processes is not a simple task. Author of [7] had reported that a great part of challenge is the modeling of interconnections of urban processes that are resulting in a complex spatial and dynamic behavior. To contribute in overcoming this challenge, a novel modeling is proposed which answers to how to model land use, population of an urban area and their dynamics and how to interconnect the four mentioned urban processes in order to keep track of the outputs of the simulation over a calendar of time.

The paper is structured as follows: the work is put firstly into its context by presenting some related conventional and advanced RM models; secondly, it outlines specifications of advanced RM models, justifies the use of agent cellular automata approach and then presents the proposed novel modeling with its sub-models. Finally, a conclusion is given to highlight usefulness of this model for boosting modeling, coding and development of residential mobility applications.

\section{Classical AND AdVANCED RM Models}

Residential mobility is a topic of large concern to urban researchers [8]-[14]. It concentrates on causes, effects and statistic rates of households' relocation decision of an urban area. A good understanding of causes, effects and rates would be of great help for urban planners and decisions makers.

Residential mobility models could be classified on two categories conventional and advanced models. Conventional models [9], [15]-[17] are concentrating on rates of mobility for different households categories. It uses generally cross sectional census data and tries to answer to questions such as why an urban area is representing a big rate of mobility, why a member or household category move frequently. These studies are limited in goals, and focus only on understanding drivers and effects of residential mobility for a given urban area.

With advancement in computer algorithms and GIS spatial analysis, advanced residential mobility models are gradually replacing conventional models. These models combine in addition to residential mobility other urban processes such as housing choice, urban growth, transport system, etc. [18], [19] [3], [4]. Models of this category use series of socioeconomic census data, households' census data, demographic data and spatial data. Models of these complex systems could be constructed only if urban systems are considered as spatial, dynamic, self-organizing and computational systems.

\section{SPECIFICATION OF ADVANCED RM MODELS}

Residential mobility is a phenomenon that takes place in an urban city over a calendar of years. Households could decide yearly to move from one location to another. When they decide to move, then subsequently they decide to choose a new housing. Decision of relocation is an algorithm that uses households' learning census data and decides if a given household desire to move to a new housing or not. After decision of relocation comes Housing Choice which is also an 
algorithm that uses socioeconomic census data and urban planning data such as properties and quality of housing and neighborhood and give each household the capability to choose from a selection of housings a better one. Structure of land use of the City could change yearly e.g., new built-up area, new industrial area etc. Change of infrastructure between two successive years could be introduced manually using planned infrastructure data or automatically using land use prediction algorithms. Planned infrastructure data are generally plans of new constructions of a City for a horizon of years e.g., 10 years. Land use prediction is an algorithm that uses series of past aerial or satellite imagery and then predicts land use change of next years. Population growth could be seen as an engine for residential mobility. Population grows, in fact households, for one reason or another (birth of a member, death of a member, employment, marriage, departure etc.). Population growth is also an algorithm that uses learning statistic and demographic data of households of the City and project next households' generations. Based on this description, the oncoming model has to give answers on how to model the urban space, population and their dynamics over a calendar of time. More specifically, the model has to keep track of households' movements, population growth, land use dynamics. So it could for each given year computes statistics data about mobility, population growth and urban expansion etc. The City should be considered as a result of interaction of individual smallest units i.e., households and spatial units particularly housings. In fact, the oncoming model will be a virtualization of the City where households interact with the environment e.g., districts and make residential actions such as relocation or housing choice. The interaction could not be done with a top-down approach; the need for a bottom-up approach is arisen. Next section will be devoted to discuss the utility of Agent Based Modeling and Cellular Automata bottom-up approaches.

\section{Why Agent Cellular Automata Approach}

The City where urban processes take place, could be represented by two layers, one for individual households which move and choose housings, and the other for infrastructure units such as housings, transport segment, green space etc. to model urban processes, researchers have used a number of approaches which can be generally classified in two categories: top-down and bottom-up models as mentioned in [12].

With the continuous development of computer model, the bottom-up models have gradually replaced the top-down models in modeling urban dynamics. In a bottom-up approach, systems are considered as result of all smallest units' actions. Among these bottom-up approaches, cellular automata (CA) have been widely used for modeling and simulating infrastructure layer of urban areas [5], [20]-[23]. CA to project spatial forms of an urban area, it abstracts land field using a lattice of discrete cells, and presents the overall behavior from simple local rules. However, "bottom-up" CA models cannot incorporate decision of urban actors (e.g., households) and CA cells cannot move in space. This is why Multi-Agent Systems (MAS) are receiving currently much attention in urban modeling [24]-[27]. MAS could analyze potential actors of urban systems in the real world. MAS consist of a number of "agents" able to model interaction between humans and their environment, and can make choices and decisions in response to this interaction. Individual behavior of these agents determines the behavior of the entire system. None of these approaches could solely represent the two layers (infrastructure layer and layer of urban actors e.g., households). A good modeling approach is a mixture of CA and MAS approaches. CA will represent urban space and its smallest units e.g., housings, transport segment, green space etc. MAS will represent actors of the urban space such as individual households or organizations.

\section{THE PROPOSED MOdELLING}

The proposed modeling contains six models based UML 2.0 diagrams which model parts of the system from different views. All models have designed using Entreprise architect [28]. The first four models describe land use, population and their dynamics. The fifth model describe how interconnection of residential mobility, housing choice, land use change and population growth processes is done. The last one describe the structure of the main objects of the system which are the composite' objects responsible of tracking snapshots of the system over time.

\section{A. Land use representation}

To represent land use, a Cellular automaton based model is designed as in Fig. 1. Its basics elements are cells, states and 2D grid. Each cell will represent a spatial unit of the studied land use. Each cell has a state that represents soil occupancy. CA states number is finite and it is determined based on the classification of the studied land area. Each cell which is identified by geographic position ( $\mathrm{x}$ and $\mathrm{y}$ ) has neighbors depending on the neighborhood's type (e.g. Van Neumann, Moore, etc.) or neighborhood's range (e.g., range $=400$ meter). The method transitTo (States) describe how a cell transit from a current state to another. The Grid class is a composition of Cell class. After code generation, the Grid will contain a LinkedList collection <Cell> to store all cells representing the land use. The State Collection is a composite of CA states. After code generation, State Collection will contain a LinkedList collection <State> to store states of the studied system. The CA model is generic and extensible, new derived models could be created depending on specification of newly studied land use in terms of CA states number, CA transition rules and land use map format etc.

\section{B. Population representation}

To represent population of the studied, an agent based model is designed as in Fig. 2. The central element of the MAS model is the Household ( $\mathrm{HH})$. This later is composed of one householder and many members. The HH lives in a Housing that is located in a cell of the Grid. The MAS model reuses an existent MAS framework (e.g., JADE). Thus, the HH extends a MAS agent of an extern framework. As result, each $\mathrm{HH}$ of the population is represented by a MAS agent which is interconnected with its correspondent housing.

\section{Population dynamics}

To represent population dynamics, the following model in Fig. 3 is proposed. The model describes how to track population generations of a studied area over a calendar of years in order to establish an observatory of population growth 
but also an observatory of population movements. Each Household is stored with a unique identifier. Population class is a composition of Household class. After code generation, population class will contain a map collection Map<id,Household> to store all Households of a given time step.

Each Population is stored with a given iteration. PopulationArchive is a composition of Population class which means in other words that the PopulationArchive contains all population generations. After code generation, PopulationArchive will contain a collection Map<iteration,Popuation> to store each population generation with its specific iteration. Depending on models, first population at time $\mathrm{t}_{0}$ comes from census data. Next generations of populations are projected using projection algorithms and learning demographic data.

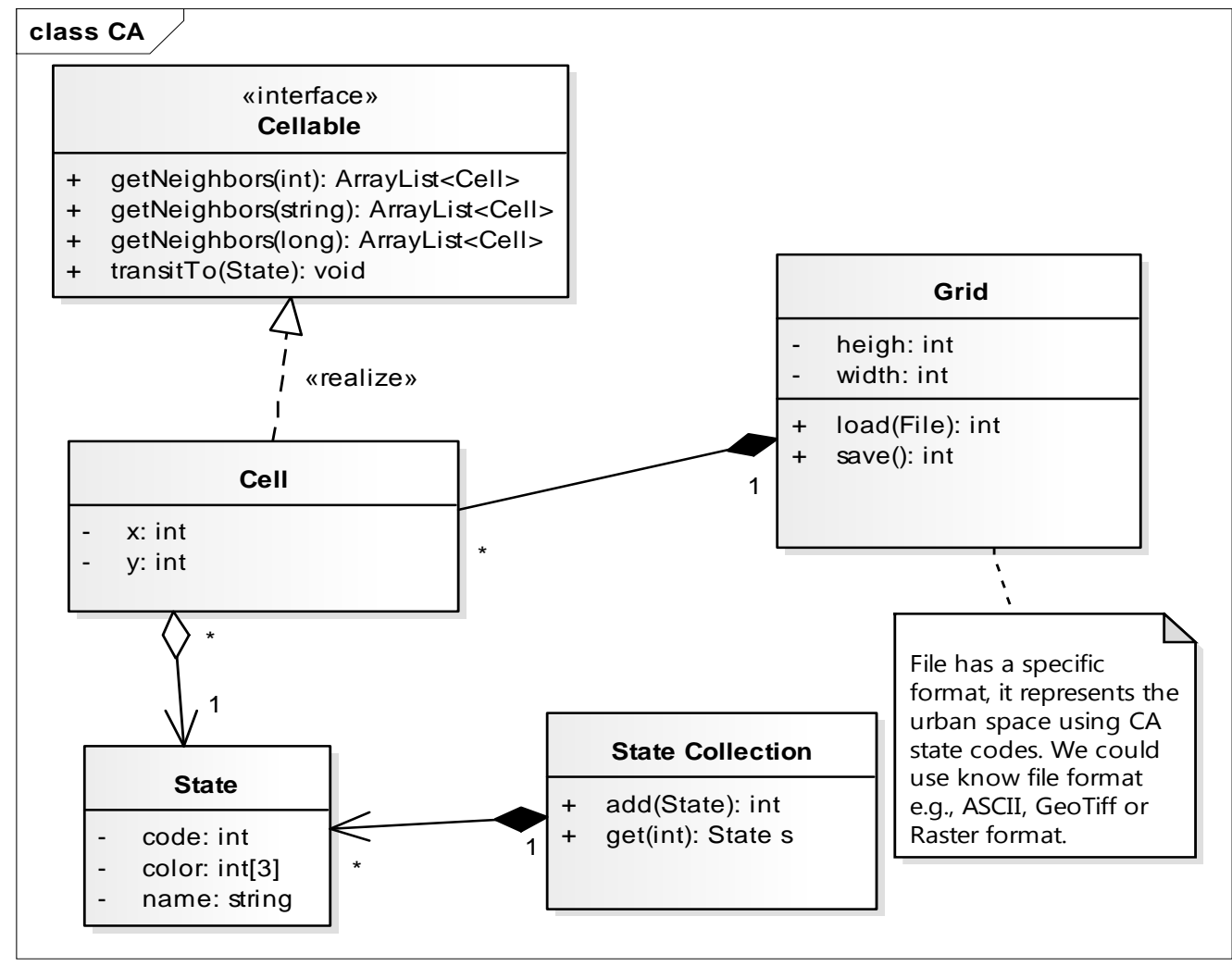

Fig. 1. CA model.

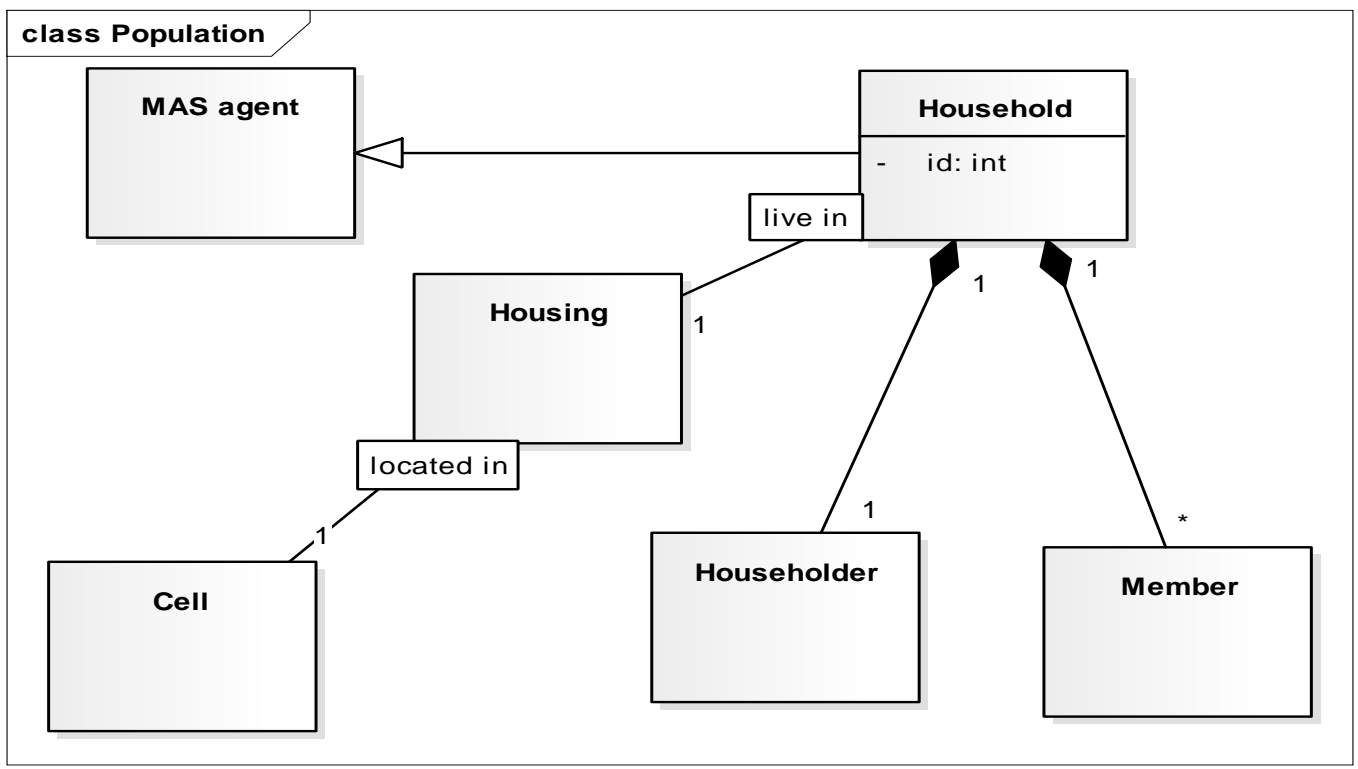

Fig. 2. MAS model. 


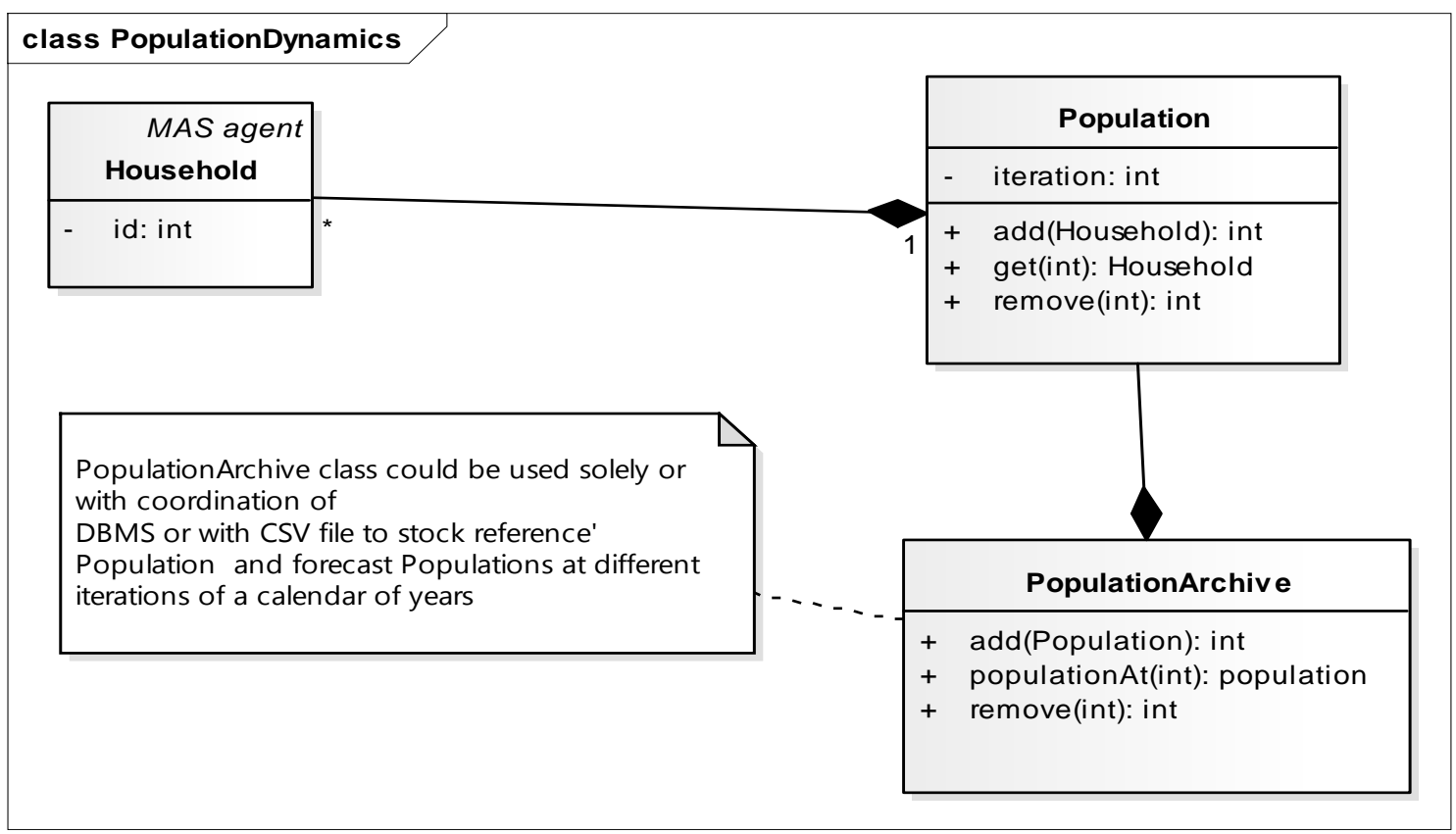

Fig. 3. Population growth model.

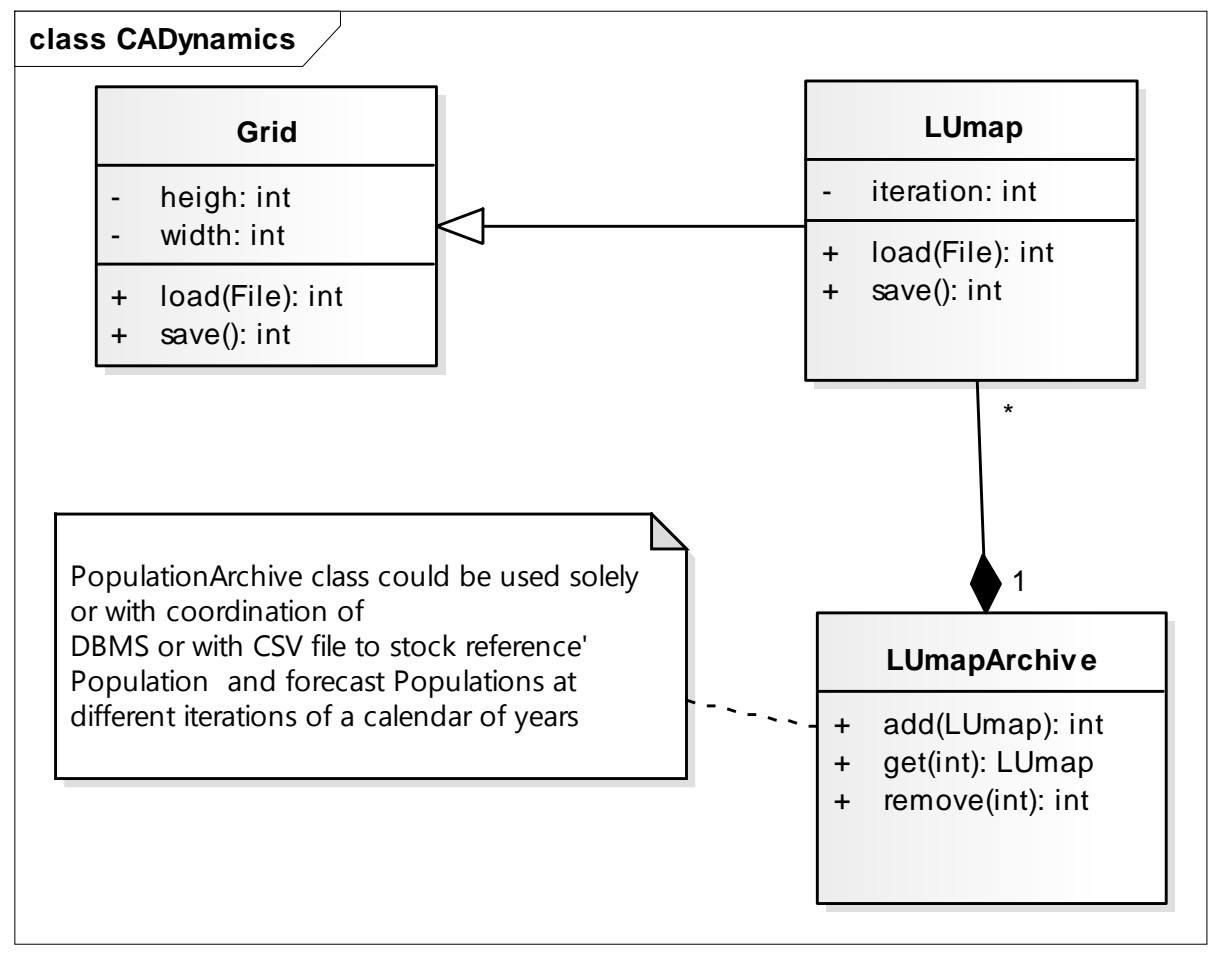

Fig. 4. Land use dynamics model.

\section{Land use dynamics}

To represent land use dynamics, the model in Fig. 4 is proposed. The model describes how to track land use dynamics of a studied area over a calendar of years. LUmap class extends Grid class. Thus LUmap will represent soil occupancy of the studied area in a given iteration. LUmapCollection is a composite of many LUmap. A Land use map at time $t_{i}$ will change in $t_{i+1}$. So to track evolution of land use for a calendar of years, LUmapCollection will use a map collection of LUmap instances Map<iteration, LUmap> to store LUmaps, each one with its specific iteration. As result, dynamics of land use is archived from its first year of simulation till last year. Depending on models, first LUmaps that represents soil occupancy of the studied area could be loaded from a file with a specific or known format e.g. ASCII, GeoTIFF, Raster or Vector format. Next LUmaps are forecasted using algorithms and learning socioeconomic and spatial data. 


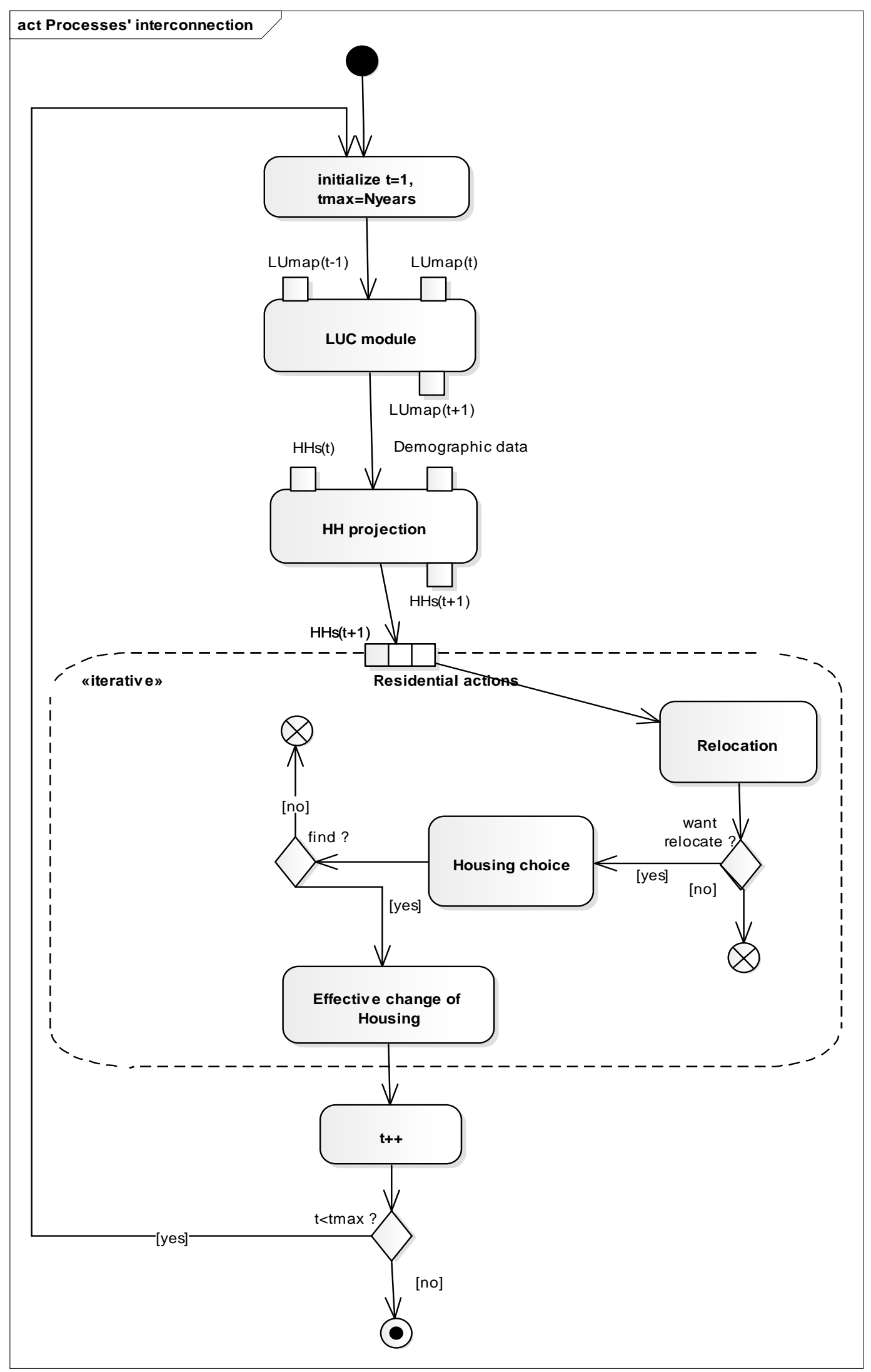

Fig. 5. Process interconnection's model. 


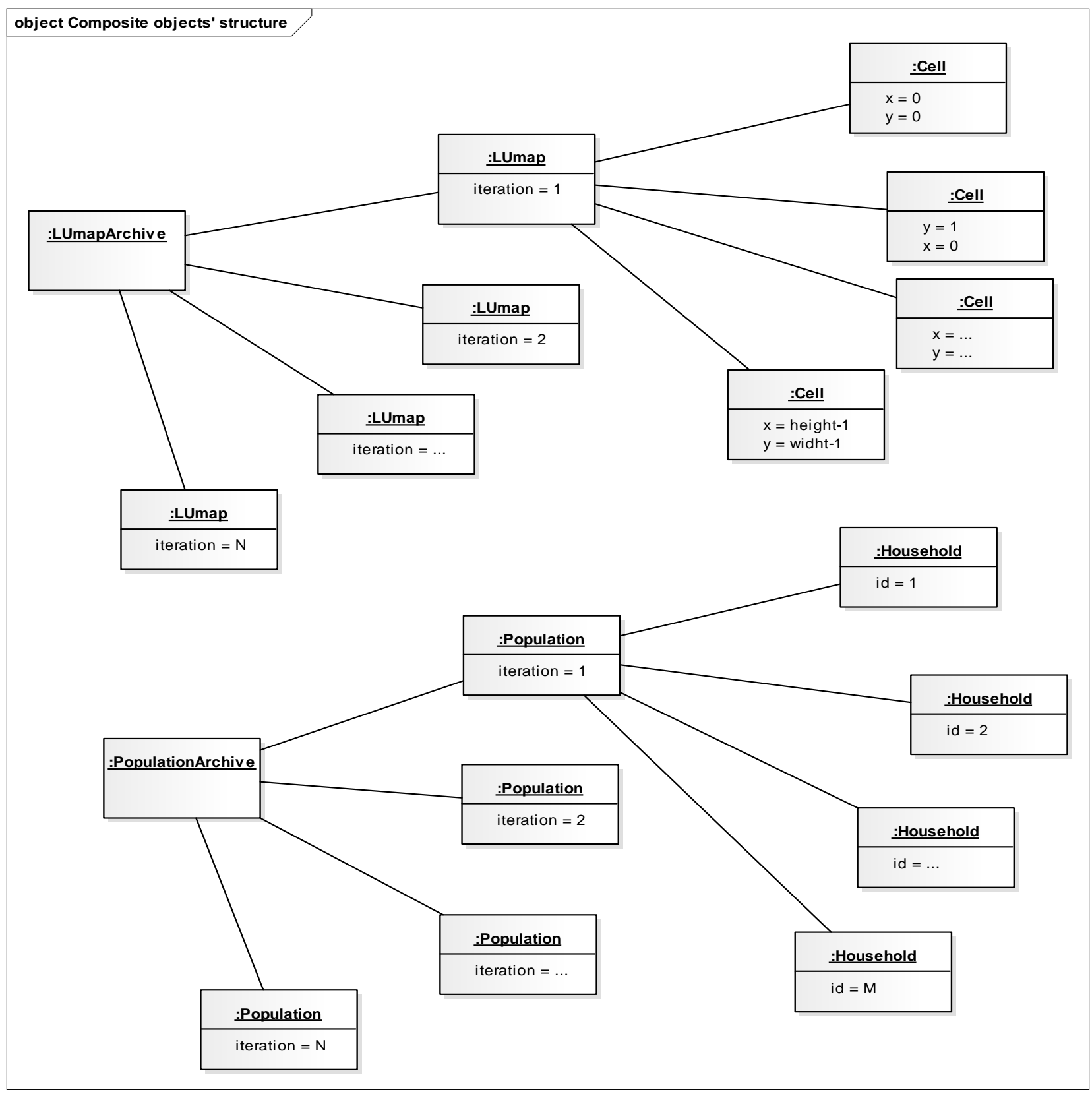

Fig. 6. Structure of composite' objects.

\section{E. Processes' interconnection}

The model encapsulates four algorithms. To model their interconnection, the model in Fig. 5 is proposed. It describes object and control flow between algorithms which are represented by action entities. It is assumed that maps at time $\mathrm{t}_{0}$ and $t_{1}$, population at time $t_{1}$, demographic data indexes and census data are already loaded in the model. The model iterates for number of years previously parametered. In each iteration $t_{i}$ the model begins by LUC module then $\mathrm{HH}$ projection to forecast $\mathrm{HH}$ at time $\mathrm{t}_{\mathrm{i}+1}$. LUC module could predict structure of next LUmaps from past LUmaps using prediction algorithms; however, in case of simulation based scenarios, next LUmaps could be parameterized manually in the model. The remaining expansion region will be executed for each $\mathrm{HH}$ from the list of $\mathrm{HHs}$ at time $\mathrm{t}_{\mathrm{i}+1}$. Relocation algorithm computes for each household relocation propensity. Housing choice algorithm explores the neighborhood and look for the best suitable housing. All $\mathrm{HH}$ agents are fed by these residential actions. If a $\mathrm{HH}$ decide to relocate based on relocation propensity, and found a suitable housing then it will effectively change its housing.

\section{F. Structure of composite' objects}

To represent objects' structure of the system, the model in the Fig. 6 is proposed, which depicts only composite objects. The model of the system contains one LUmapArchive which manage many LUmap objects. Each of which is a snapshot of the Land use at a given time. Each LUmap object contains a large number of Cell objects. Similarly, PopulationArchive contains many population objects. Each of which is a snapshot 
of the population at a precise time. Each population object contains a large number of Household objects.

\section{CONCLUSION}

The paper presented related research works of residential mobility, which are classified on two main categories: the classical residential mobility models which are limited in goals in contrast to advanced residential mobility models that are more realistic and effective thanks to the integration of many urban processes. It outlined also specifications of advanced residential mobility applications which should be capable firstly of tracking households' mobility, households' growth, households' housing' choice and land use dynamics over a calendar of years and secondly of interconnecting urban processes on a bottom-up approach that give the model its power of micro simulation.

After that, the paper exposed the new advanced residential mobility modeling and depicted its way to handle space, population, and residential actions of individual households. What is interesting about the model is that it used a bottom-up mixed approach. The City, in which urban phenomena take place, is considered as an emerging and auto-organized system where the global system dynamics are a set of individual behavior of smallest units i.e., households and housing. The proposed modeling is of significance and it could be used to give insights on residential mobility modeling and to boost modeling, development and coding of ulterior advanced residential mobility applications. Further works are planned. The proposed modeling could be improved in a way to support more the Model View Controller (MVC) architecture. The proposed modeling is also planned to be the core of a future residential mobility simulation Framework.

\section{REFERENCES}

[1] El-arbi El-alaouy, Khadija Rhoulami, and Moulay Driss Rahmani, "Towards an agent based model for simulating residential mobility and urban expansion," Proceedings of the Mediterranean Conference on Information I\& Communication Technologies. Springer International Publishing, 2016. p. 343-351., 2015.

[2] Dagmar Haase, Sven Lautenbach, and Ralf Seppelt, "Modeling and simulating residential mobility in a shrinking city using an agent-based approach," Environmental Modelling I\& Software, vol. 25, pp. 12251240,2010

[3] Veronika Gaube and Alexander Remesch, "Impact of urban planning on household's residential decisions: An agent-based simulation model for Vienna," Environmental modelling I\& software, vol. 45, pp. 92-103, 2013.

[4] Jean-Philippe Antoni and Gilles Vuidel, MobiSim: un modèle multiagents et multi-scalaire pour simuler les mobilités urbaines, 2010.

[5] Edwige Dubos-Paillard, Yves Guermond, and Patrice Langlois, "Analyse de l'évolution urbaine par automate cellulaire. Le modèle SpaCelle," L $>$ espace g

[6] Sean Luke, Claudio Cioffi-Revilla, Liviu Panait, Keith Sullivan, and Gabriel Balan, "Mason: A multiagent simulation environment," Simulation, vol. 81, pp. 517-527, 2005.

[7] Robert M. Itami, "Simulating spatial dynamics: cellular automata theory," Landscape and urban planning, vol. 30, pp. 27-47, 1994.

[8] Frans M. Dieleman, "Modelling residential mobility; a review of recent trends in research," Journal of housing and the built environment, vol. 16, pp. 249-265, 2001.
[9] Thierry Debrand and Claude Taffin, "Les facteurs structurels et conjoncturels de la mobilité résidentielle depuis 20 ans," Economie I\& Statistique, 2005 .

[10] René Jordan, Mark Birkin, and Andrew Evans, "Agent-based modelling of residential mobility, housing choice and regeneration," in Agentbased models of geographical systems.: Springer, 2012, pp. 511-524.

[11] Arden Craig Brummell, "A theory of intraurban residential mobility behaviour," Ph.D. dissertation 1977.

[12] Itzhak Benenson, "Multi-agent simulations of residential dynamics in the city," Computers, Environment and Urban Systems, vol. 22, pp. 2542, 1998.

[13] Nicolas Coulombel, "Residential choice and household behavior: State of the Art," Ecole Normale Sup

[14] Ronghui Tan, Yaolin Liu, Kehao Zhou, Limin Jiao, and Wei Tang, “A game-theory based agent-cellular model for use in urban growth simulation: A case study of the rapidly urbanizing Wuhan area of central China," Computers, Environment and Urban Systems, vol. 49, pp. 1529, 2015.

[15] Helmuth Cremer, Henry-Jean Gathon, and others, "Les déterminants de la mobilité résidentielle: une analyse probit," Brussels Economic Review, vol. 115, pp. 53-75, 1987.

[16] Sara Anderson, Tama Leventhal, and Véronique Dupéré, "Residential mobility and the family context: A developmental approach," Journal of Applied Developmental Psychology, vol. 35, pp. 70-78, 2014.

[17] Ahmed Lahlimi Alami et al., Les Cahiers du Plan $N^{\circ} 45$ - Septembre / Octobre 2013 Agdal - Rabat, 2013.

[18] Paul Waddell and Gudmundur F. Ulfarsson, "Introduction to urban simulation: Design and development of operational models," in Handbook of transport geography and spatial systems.: Emerald Group Publishing Limited, 2004, pp. 203-236.

[19] Itzhak Benenson, "Agent-based modeling: From individual residential choice to urban residential dynamics," Spatially integrated social science: Examples in best practice, vol. 42, pp. 67-95, 2004.

[20] Kenneth Mubea, Roland Goetzke, and Gunter Menz, "Applying cellular automata for simulating and assessing urban growth scenario based in Nairobi, Kenya," International Journal of Advanced Computer Science and Applications, vol. 5, pp. 1-13, 2014.

[21] Diana Mitsova, William Shuster, and Xinhao Wang, "A cellular automata model of land cover change to integrate urban growth with open space conservation," Landscape and Urban Planning, vol. 99, pp. 141-153, 2011.

[22] Daru Kusuma Purba, "Implementation of Pedestrian Dynamic In Cellular Automata Based Pattern Generation," International Journal of Advanced Computer Science and Applications, vol. 7, pp. 65-70, 2016.

[23] Kohei Arai and S. Sentinuwo, "Spontaneous-braking and lane-changing effect on traffic congestion using cellular automata model applied to the two-lane traffic," IJACSA) International Journal of Advanced Computer Science and Applications, vol. 3, 2012.

[24] Hasan Omar Al-Sakran, "Intelligent traffic information system based on integration of Internet of Things and Agent technology," International Journal of Advanced Computer Science and Applications (IJACSA), vol. 6, pp. 37-43, 2015.

[25] Fatimazahra BARRAMOU and Malika ADDOU, "An agent based approach for simulating complex systems with spatial dynamicsapplication in the land use planning," IJACSA) International Journal of Advanced Computer Science and Applications, vol. 3, 2012.

[26] Harjot Kaur, Karanjeet Singh Kahlon, and Rajinder Singh Virk, "Migration dynamics in artificial agent societies," Int. J. Adv. Res. Artif. Intell, vol. 3, pp. 39-47, 2014.

[27] Verda Kocabas and Suzana Dragicevic, "Bayesian networks and agentbased modeling approach for urban land-use and population density change: a BNAS model," Journal of geographical systems, vol. 15, pp. 403-426, 2013.

[28] Entreprise architect Sparx, http://www.sparxsystems.com/ 